\title{
ARTICLE
}

Received 4 Mar 2014 | Accepted 19 May 2014 | Published 19 Jun 2014 DOl: 10.1038/ncomms5169

\section{X-ray structure of a CDP-alcohol phosphatidyltransferase membrane enzyme and insights into its catalytic mechanism}

Przemyslaw Nogly ${ }^{1, \star}$, Ivan Gushchin ${ }^{2,3,4,5, \star}$, Alina Remeeva ${ }^{2,3,4, \star}$, Ana M. Esteves ${ }^{1}$, Nuno Borges ${ }^{1}$, Pikyee Ma ${ }^{1}$, Andrii Ishchenko 6,7, Sergei Grudinin ${ }^{8,9,10}$, Ekaterina Round $2,3,4,6$, Isabel Moraes $11,12,13$, Valentin Borshchevskiy ${ }^{5,6}$, Helena Santos ${ }^{1}$, Valentin Gordeliy ${ }^{2,3,4,5,6}$ \& Margarida Archer ${ }^{1}$

Phospholipids have major roles in the structure and function of all cell membranes. Most integral membrane proteins from the large CDP-alcohol phosphatidyltransferase family are involved in phospholipid biosynthesis across the three domains of life. They share a conserved sequence pattern and catalyse the displacement of CMP from a CDP-alcohol by a second alcohol. Here we report the crystal structure of a bifunctional enzyme comprising a cytoplasmic nucleotidyltransferase domain (IPCT) fused with a membrane CDP-alcohol phosphotransferase domain (DIPPS) at $2.65 \AA$ resolution. The bifunctional protein dimerizes through the DIPPS domains, each comprising six transmembrane $\alpha$-helices. The active site cavity is hydrophilic and widely open to the cytoplasm with a magnesium ion surrounded by four highly conserved aspartate residues from helices TM2 and TM3. We show that magnesium is essential for the enzymatic activity and is involved in catalysis. Substrates docking is validated by mutagenesis studies, and a structure-based catalytic mechanism is proposed.

\footnotetext{
${ }^{1}$ Instituto de Tecnologia Química e Biológica, Universidade Nova de Lisboa (ITQB-UNL), Av. República, EAN, 2780-157 Oeiras, Portugal. ${ }^{2}$ Université Grenoble Alpes, IBS, F-38000 Grenoble, France. ${ }^{3}$ CNRS, IBS, F-38000 Grenoble, France. ${ }^{4}$ CEA, IBS, F-38000 Grenoble, France. ${ }^{5}$ Interdisciplinary Center for Basic Research, Moscow Institute of Physics and Technology, 141700 Dolgoprudniy, Russia. ${ }^{6}$ Institute of Complex Systems (ICS), ICS-6: Structural Biochemistry, Research Centre Juelich, 52425 Juelich, Germany. ${ }^{7}$ Institute of Crystallography, University of Aachen (RWTH), 52056 Aachen, Germany. ${ }^{8}$ University Grenoble Alpes, LJK, F-38000 Grenoble, France. ${ }^{9}$ CNRS, LJK, F-38000 Grenoble, France. ${ }^{10}$ Inria, F-38000 Grenoble, France. ${ }^{11}$ Department of Life Sciences, Imperial College London, London SW7 2AZ, UK. ${ }^{12}$ Membrane Protein Laboratory, Diamond Light Source, Harwell Science and Innovation Campus, Didcot, Chilton OX11 ODE, UK. ${ }^{13}$ Research Complex at Harwell Rutherford, Appleton Laboratory, Harwell, Oxford, Didcot OX11 OFA, UK. * These authors contributed equally to this work. Correspondence and requests for materials should be addressed to V.G. (email: valentin.gordeliy@ibs.fr) or to M.A. (email: archer@itab.unl.pt).
} 
P hospholipids are not only major structural components of biological membranes but they also have key roles in cell physiology, regulation and maturation of numerous cellular processes ${ }^{1}$. Disruption of phospholipid homeostasis is associated with several human diseases, and has a crucial role in pathogen invasion, infectivity and virulence ${ }^{1,2}$. A better understanding of their metabolic pathways and regulation should help development of chemotherapeutic drugs against cancer and various infectious diseases. As an example, the synthesis of phosphatidylinositol is essential for growth of Mycobacterium smegmatis $^{3}$ and differs from the human pathway ${ }^{4}$, highlighting the respective biosynthetic enzymes as promising targets for the development of drugs to treat tuberculosis, the second cause of mortality by infectious diseases.

To shed light into de novo biosynthesis of phospholipids, we characterized the structure of a representative from the CDPalcohol phosphatidyltransferase family (CDP-OH_P_trans). Kennedy et al. ${ }^{5,6}$ first described these enzymes using both an insoluble substrate (diacylglycerol) and a soluble substrate (CDPalcohol). To date, more than 12,750 sequences are classified as CDP-OH_P_trans in UniProt Knowledgebase. Members of this family are integral membrane proteins that share a conserved sequence pattern and usually comprise 150-400 amino-acid residues. They catalyse the displacement of CMP from a CDPalcohol by a second alcohol with formation of a phosphodiester bond and concomitant breaking of a phosphoride anhydride bond, having a key role in the biosynthesis of essential phospholipids. Figure 1 illustrates the participation of these

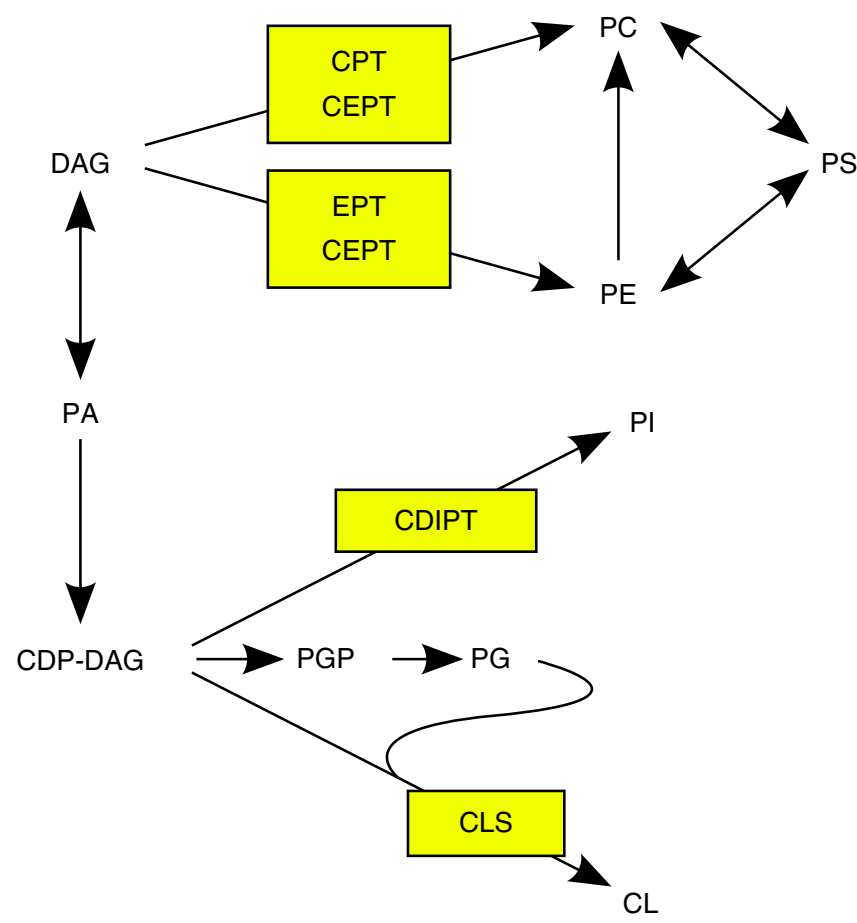

Figure 1 | Pathways of (glycero)phospholipid biosynthesis in mammalian cells. The biosynthesis starts either from diacylglycerol (DAG) or phosphatidic acid (PA), and results in production of phosphatidylcholine $(P C)$, phosphatidyletanolamine (PE), phosphatidylserine (PS),

phosphatidylinositol (PI) and cardiolipin (CL), adapted from Hermansson et al. ${ }^{7}$ The intermediate metabolites are CDP-DAG, phosphatidylglycerol phosphate (PGP) and phosphatidylglycerol (PG). The CDP-alcohol phosphatidyltransferase family enzymes in human are highlighted; CPT, cholinephosphotransferase 1; CEPT, choline/ethanolaminephosphotransferase 1; EPT, ethanolaminephosphotransferase 1; CDIPT,

phosphatidylinositol synthase 1; and CLS, cardiolipin synthase. enzymes in the biosynthesis of all major (glycero)phospholipids in mammalian cells ${ }^{7}$, including human phosphatidylinositol synthase, choline/ethanolaminephosphotransferase and cardiolipin synthase. Despite the important function of CDP-alcohol phosphotransferases, no structure had been yet characterized for any member.

Since very often membrane proteins, especially those from human sources, resist crystallization we selected an enzyme from the hyperthermophilic archaeon Archaeoglobus fulgidus, which comprises CTP:L-myo-inositol-1-phosphate cytidylyltransferase (IPCT) fused with CDP-L-myo-inositol:myo-inositolphosphotransferase, also designated di-myo-inositol-1,3'-phosphate- $1^{\prime}$ phosphate synthase (DIPPS), a member of the CDP-alcohol phosphatidyltransferase family. The bifunctional enzyme IPCT/ DIPPS catalyses two consecutive steps of di-myo-inositol-1,3'phosphate (DIP) biosynthesis ${ }^{8-10}$ (Fig. 2). For sake of simplicity 'L' and ' $m y o^{\prime}$ ' will be omitted hereafter. First, inositol-1-phosphate is activated to CDP-inositol by IPCT. CMP is then displaced from CDP-inositol by inositol-1-phosphate with formation of DIP-phosphate (DIPP) by DIPPS. Finally, DIPP is dephosphorylated to DIP by a DIPP-phosphatase. DIP content increases drastically at supraoptimal growth temperatures and was shown to stabilize proteins in vitro ${ }^{8,11}$. Accordingly, DIP was proposed to be a major protecting molecule in a number of (hyper)thermophilic species of archaea and bacteria. In most organisms, both the IPCT and DIPPS activities are present in a single gene product, but separate genes can also be found ${ }^{8,12}$.

Here we present the three-dimensional structure of an archaeal CDP-alcohol phosphatidyltransferase (DIPPS) coupled with a cytidylyltransferase (IPCT) at $2.65 \AA$ resolution. We analyse the functional role of highly conserved amino-acid residues by sitedirected mutagenesis studies, dock substrates into identified pockets and propose a catalytic mechanism. This structure opens new avenues for homology modelling of other $\mathrm{CDP}-\mathrm{OH}$ phosphotransferases, namely those with biomedical interest.

\section{Results}

Structure determination. The bifunctional enzyme IPCT/DIPPS from A. fulgidus was produced in Escherichia coli and purified by immobilized metal affinity chromatography. The recombinant protein was crystallized from sample preparations using Triton $\mathrm{X}-100$ for membrane extraction and protein solubilization. Crystals were grown using the in meso crystallization method ${ }^{13}$. They belong to the orthorhombic space group $\mathrm{P} 2{ }_{1} 2{ }_{1} 2$ with unit cell parameters of $a=41.37, b=107.58$ and $c=123.95 \AA$ (Table 1). One IPCT/DIPPS molecule is present in the crystal asymmetric unit corresponding to a Matthews coefficient ${ }^{14}$ of $2.87 \AA^{2} \mathrm{Da}^{-1}$ and a solvent content of $\sim 57 \%$. This molecule interacts extensively with another molecule related by crystallographic symmetry (Supplementary Fig. 1). The protein molecules are organized in the crystal as a stack of membrane layers, typical for in meso crystallization (type I membrane protein crystals ${ }^{15}$ ), with interlayer contacts relying entirely on the IPCT cytoplasmic domain (Supplementary Fig. 1). The structure was solved by molecular replacement using the coordinates of the IPCT domain we previously reported ${ }^{16}$ and refined to a resolution of $2.65 \AA$ with $R_{\text {work }} / R_{\text {free }}$ values of $24.5 \%$ and $30 \%$, respectively (Table 1). The final model comprises 408 amino-acid residues, 1 magnesium ion, 9 water molecules and 4 lipid fragments. The electron density maps are generally of good quality (Supplementary Fig. 2a). The soluble IPCT domain is somewhat less ordered than the membrane DIPPS one (average B-factors of IPCT and DIPPS backbone atoms are 70.9 and $50.5 \AA^{2}$, respectively; Supplementary Fig. $2 b$ ). 

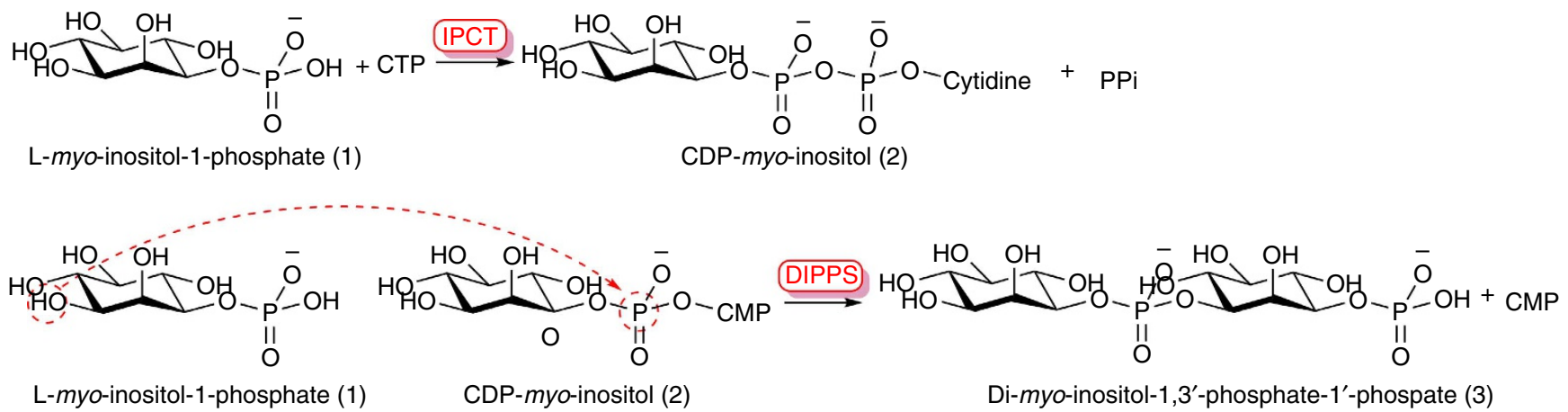

Figure 2 | Catalytic reactions of IPCT/DIPPS bifunctional enzyme. Biosynthesis of di-myo-inositol-1,3'-phosphate-1'-phosphate (DIPP). IPCT-CTP:L-myoinositol-1-phosphate cytidylyltransferase; DIPPS-CDP-L-myo-inositol:myo-inositolphosphotransferase or DIPP synthase; PPi-pyrophosphate; CMP, CDP, CTP- cytidine mono-, di-, tri- phosphate, respectively. The dashed red line represents the nucleophilic attack of the hydroxyl group (C3) of inositol-1phosphate on the $\beta$-phosphoryl of CDP-inositol with formation of a phosphodiester bond.

\begin{tabular}{|c|c|}
\hline Data collection & \\
\hline Space group & $\mathrm{P} 22_{1} 2_{1} 2$ \\
\hline Cell dimensions & $41.37,107.58,123.95$ \\
\hline $\begin{array}{l}a, b, c(A) \\
\alpha, \beta, \gamma\left({ }^{\circ}\right)\end{array}$ & $\begin{array}{c}41.3 /, 107.58,123.95 \\
90,90,90\end{array}$ \\
\hline Resolution $(\AA)$ & $61.82-2.65(2.79-2.65)^{\star}$ \\
\hline No. unique reflections & 15,952 \\
\hline$R_{\text {merge }}^{\dagger}$ & $0.203(1.063)$ \\
\hline$R_{\text {pim }}^{\ddagger}$ & $0.081(0.469)$ \\
\hline$C C^{\star \S}$ & $0.991(0.513)$ \\
\hline$|/ \sigma|$ & $7.7(1.7)$ \\
\hline Completeness (\%) & $99.9(99.9)$ \\
\hline Redundancy & $7.2(5.8)$ \\
\hline \multicolumn{2}{|l|}{ Refinement } \\
\hline Resolution ( $\AA$ ) & $53.85-2.65$ \\
\hline$R_{\text {work }} / R_{\text {free }}(\%)$ & $24.3 / 30.0$ \\
\hline \multicolumn{2}{|l|}{ Number of atoms } \\
\hline Protein & 3,112 \\
\hline $\mathrm{Mg}^{2+}$ & 1 \\
\hline Lipid fragments & 4 \\
\hline Water & 9 \\
\hline \multicolumn{2}{|l|}{ Average $B$-factor $\left(\AA^{2}\right)$} \\
\hline Protein & 61.4 \\
\hline $\mathrm{Mg}^{2+}$ & 58.7 \\
\hline Lipid fragments & 58.5 \\
\hline Water & 48.3 \\
\hline \multicolumn{2}{|l|}{ Ramachandran } \\
\hline Residues in favored regions (\%) & 96.3 \\
\hline Residues in disallowed regions (\%) & 0.5 \\
\hline \multicolumn{2}{|l|}{ R.m.s. deviations } \\
\hline Bond lengths $(\AA)$ & 0.014 \\
\hline Bond angles $\left({ }^{\circ}\right)$ & 0.791 \\
\hline
\end{tabular}

*Highest resolution shell is shown in parenthesis.

$\dagger R_{\text {merge }}=\sum_{h k l} \sum_{i}\left|l_{i}(h k l)-\overline{I(h k l) \mid}\right| / \sum_{h k l} \sum_{i} l_{i}(h k l)$

$\ddagger R_{\mathrm{pim}}=\sum_{\mathrm{hkl}}[1 /(N-1)]^{1 / 2} \sum_{i}\left|l_{i}(h k l)-\overline{l(h k l)}\right| / \sum_{h k l} \sum_{i} l_{i}(h k l)$

Calculated with the programme SCALA, $R_{\text {merge }}$ and $R_{\text {pim }}$ are indicators of the precision of the final merged and averaged data set, where $I_{i}(\mathrm{hkl})$ is the observed intensity of the $i$ th measurement, $\overline{l(h k l)}$ is the average intensity of multiple observations of symmetry-related reflections and $N$ is redundancy.

${ }^{\S} \mathrm{CC}^{\star}$ coefficient as described in Karplus and Diederichs ${ }^{39}$.

Overall fold. The IPCT/DIPPS bifunctional protein forms a dimer via its transmembrane (TM) domains (Fig. 3a,b). The dimeric interface is formed by helix TM4 of one protomer protruding between helices $\mathrm{TM}^{\prime}$ and $\mathrm{TM} 4^{\prime}$ of the other protomer and flanked by TM6. The interface is stabilized mostly by hydrophobic contacts within the lipidic bilayer and several
H-bonds between polar/charged residues located at the cytoplasmic extramembrane side with a total contact area of $2,050 \AA^{2}$.

DIPPS domain contains six TM $\alpha$-helices TM1-TM6 and one shorter bent juxtamembrane helix (connector helix 2; Fig. 3a). TM2 shows a kink around Asp357 nearby the membrane interface. The intracellular side of the TM domain is large and contains many polar and charged residues, whereas the opposite side is mostly embedded in the membrane. All TMs cross the membrane, except TM5, which is shorter. Connector helices 1 and 2 lie nearly parallel to the membrane plane, and link the soluble and membrane domains. We assigned connector helix 1 to IPCT and connector helix 2 to DIPPS, based on their distribution in the organisms where IPCT and DIPPS do not belong to the same polypeptide chain (Supplementary Fig. 3). Although connector helix 2 is conserved among the DIPPsynthases, it is absent in many other CDP-alcohol phosphatidyltransferases (Supplementary Fig. 4). It wraps around TM2 and the $\mathrm{N}$ terminus of TM5. Both connector helices are amphipathic, the hydrophobic side of connector helix 2 faces the membrane and is proximal to two lipid fragments, whereas its hydrophilic side point towards the cytoplasm and connector helix 1, whose apolar residues face the proximal $\beta$-sheet of IPCT.

The cytoplasmic IPCT domain binds at the edge of the DIPPS domain (Fig. 3a). It comprises a core region formed by a central seven-stranded mixed $\beta$-sheet flanked by six $\alpha$-helices. This arrangement is reminiscent of a dinucleotide-binding Rossmann fold, typical of nucleotidyltransferases, with an additional twostranded $\beta$-sheet and a 30-residue long stretch. The sugar-binding region comprises a short antiparallel three-stranded $\beta$-sheet lying against the face of the central $\beta$-sheet where the nucleotide binds. The overall fold of the IPCT domain is very similar to the structure of that domain alone, which we previously reported ${ }^{16}$ (root mean square deviation, r.m.s.d. of $0.6 \AA$ for $\mathrm{C}_{\alpha}$ atoms). Interestingly, the IPCT domains dimerized in the crystals of the truncated one-domain construct ${ }^{16}$ via the same interface that connects the IPCT and DIPPS domains in the full-length protein.

Active site architecture and consensus sequence motif. The six TM helices of DIPPS form a central hydrophilic cavity $\sim 20 \AA$ deep. This cavity is wide open $(\sim 10-20 \AA)$ to the cytoplasm (Fig. 3a). Its entrance is flanked by three loops between TM2TM3 (residues 369-373), connectors helix 1-helix 2 (residues 291-298), and TM4-TM5 (residues 430-440). The last two loops are less ordered suggesting flexibility (Supplementary Fig. 2b), and residues 292-294 and 430-433 were not included in the model as no electron density was visible in the maps. 
Remarkably, at one side of the cavity there are four aspartate residues (Asp357, Asp360, Asp378 and Asp382) pointing to the same patch of the electron density (Fig. 4a). The last three Asp are part of the conserved sequence pattern of CDP-alcohol phosphotransferase family, $\mathrm{DG}(\mathrm{x})_{2} \mathrm{AR}(\mathrm{x})_{7,8} \mathrm{G}(\mathrm{x})_{3} \mathrm{D}(\mathrm{x})_{3} \mathrm{D}$, as defined in Prosite ${ }^{17}$, but all four aspartate residues are highlighted in the HMM logo of this family (Fig. 4b). Since $\mathrm{Mg}^{2}+$ had been used throughout the purification of IPCT/ DIPPS, we assigned a magnesium ion to this blob of density lying at the membrane interface. $\mathrm{Mg}^{2}+$ is coordinated to the carbonyl of Asp357 and carboxylate groups of Asp357, Asp360 and Asp378 (Fig. 4a), where it is expected to decrease the pKa of the surrounding aspartate residues. Asp382 is not directly coordinated to the metal ion, but is within $\mathrm{H}$-bonding distances to Asp357 and Asp378, and is $\sim 4.5 \AA$ away from Arg443. This cluster of negatively charged residues will tend to increase the $\mathrm{pKa}$ of neighbouring amino-acid residues. Because the coordination sphere of magnesium is still incomplete, it could also be engaged in binding of water molecules or the pyrophosphate moiety of CDP-inositol, as observed in some glycosyltransferases ${ }^{18}$ and kinases ${ }^{19}$.

Interestingly, the entries to the active sites of both enzymes that catalyse consecutive reactions in DIP synthesis are oriented in different directions (Fig. 3a, red arrows). It is currently not known

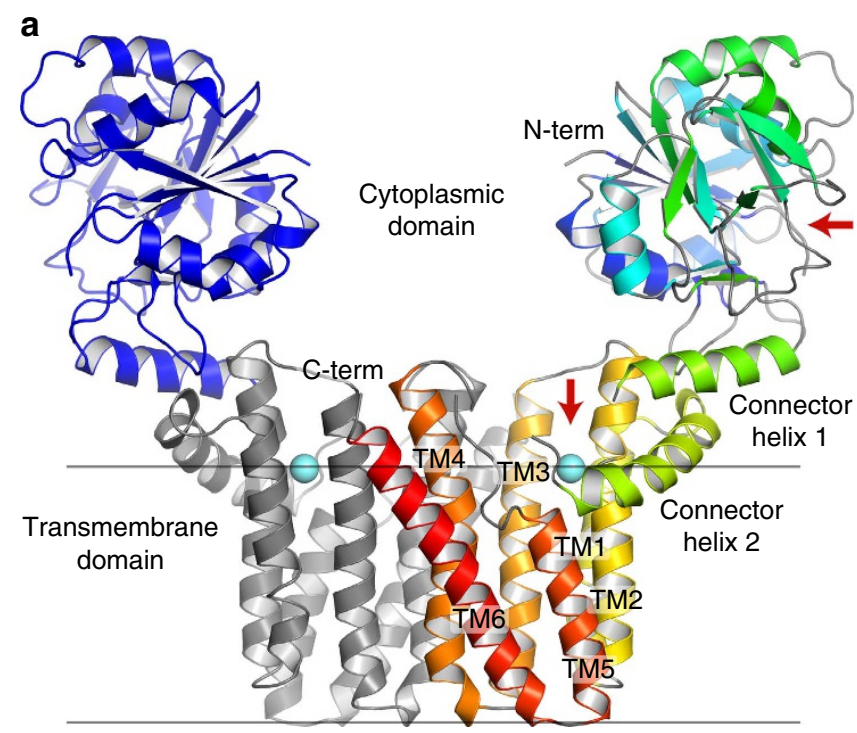

b

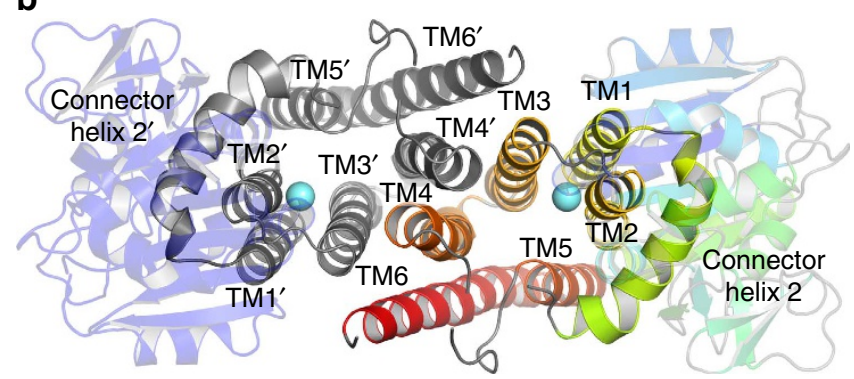

Figure 3 | X-ray structure of IPCT/DIPPS. The protein is dimerized via the TM domain. (a) One protomer is rainbow coloured and the other protomer (related by crystallographic symmetry) is in blue for cytoplasmic IPCT domain and grey for membrane DIPPS domain. Red arrows indicate the access to their active sites with a putative $\mathrm{Mg}^{2+}$ drawn as a cyan sphere. Membrane surface position (grey) was calculated with PPM server ${ }^{49}$

(b) Top view of DIPPS domain (perpendicular to the membrane plane). whether cross-talk exists between the two domains or if ipct/dipps gene fusion/separation produces any differences in the overall catalytic efficiency. It is possible that ligand binding could trigger rearrangements in the relative orientation of the two domains, as the interactions between IPCT and DIPPS domains are relatively weak (interface area of $479 \AA^{2}$, solvation free-energy gain is $-7.3 \mathrm{kcal} \mathrm{mol}^{-1}$; calculated with $\mathrm{PISA}^{20}$ ). More studies are required to clarify these questions.

Substrate binding sites and molecular docking. While searching for potential substrate binding sites, we identified three pockets on the surface of DIPPS using HOLLOW ${ }^{21}$ (Fig. 5a). Pocket 1 is the most interesting one, as it is flanked by the loop between TM2 and TM3, and lined by the family consensus residues Gly361, Ala364 and Gly374 (Figs 5b and 6). Although IPCT/DIPPS protein was crystallized in the absence of substrates, residual $2 \mathrm{~F}_{\mathrm{o}}-$ $\mathrm{F}_{\mathrm{c}}$ and $\mathrm{F}_{\mathrm{o}}-\mathrm{F}_{\mathrm{c}}$ electron densities are seen in this region that cannot be accounted for by atoms of the protein. Pocket 2 is at the bottom of the hydrophilic cavity formed by strictly conserved residues among DIPPS proteins, namely Asn304, Arg305, Ser308, Ser354, Asp357 and Arg443 (Fig. 6), sited on connector helix 2, TM2 and TM5. Pocket 3 is surrounded by helices TM4, TM5 and TM6, and loop TM5-TM6. Amino-acid residues from this loop are not conserved, and the pocket itself is far from the catalytic magnesium ion. Therefore, substrate binding within pocket 3 is very unlikely. Since pocket 1 comprises residues from the family consensus region (Fig. 6 and Supplementary Fig. 4), it should be the binding site of the cytidine moiety, a common feature among substrates of all CDP-OH phosphotransferases. In contrast, pocket 2 includes connector helix 2 and its sequence conservation is restricted to enzymes assumed to have DIPP synthase activity, which suggests it to be the binding site of inositol-1phosphate (Fig. 5c).

In order to find the best fit for the ligands within the proposed pockets, we used Autodock Vina software ${ }^{22}$ for molecular docking. First, the smaller substrate, inositol-1-phosphate, was docked into pocket 2. Then, after inositol-1-phosphate was fixed in the best position, CDP-inositol docking simulations were run. The final CDP-inositol docked pose was chosen so that CMP moiety would reside inside the highly conserved region comprising, TM2, TM3 and loop TM2-TM3, with the phosphate groups close to the catalytic magnesium ion and the hydroxyl at C3 of inositol-1-phosphate. The best positions for the two docked substrates are displayed in Fig. 5c,d.

Site-directed mutagenesis and functional assays. The production of CDP-inositol and DIPP was quantified by ${ }^{31} \mathrm{P}-\mathrm{NMR}$ in E. coli cell extracts (Fig. 7). Divalent metal ions are known to be essential for the activity of $\mathrm{CDP}-\mathrm{OH}$ phosphotransferases. IPCT/DIPPS is most efficient with $\mathrm{Mg}^{2+}$ and no activity is observed without metal ions.

Site-directed mutagenesis on conserved amino-acid residues from the family sequence pattern or considered functionally relevant (for example, for substrate binding) was carried out. HMM logo defines the conserved sequence of CDP-alcohol phosphotransferases as $\mathrm{D} 1^{357}(\mathrm{x})_{2} \mathrm{D} 2^{360} \mathrm{G}^{361}(\mathrm{x})_{2} \mathrm{~A}^{364} \mathrm{R}^{365}(\mathrm{x})_{8} \mathrm{G}^{374}$ $(\mathrm{x})_{3} \mathrm{D} 3^{378}(\mathrm{x})_{3} \mathrm{D} 4^{382}$ (superscript numbering corresponding to IPCT/DIPPS sequence; Fig. 4b). Mutations of these aforementioned four aspartates to alanine or asparagine inactivated the enzyme, except for D357N, which resulted in a very low activity (Fig. 4c). These aspartate residues are part of the hydrophilic active site cavity and are close to the magnesium ion. Moreover, mutations of consensus residues Ala364 and Arg365 to methionine caused a considerable decrease of DIPPS activity (Fig. 4c). These residues are located at TM2 and lining pocket 1 
a

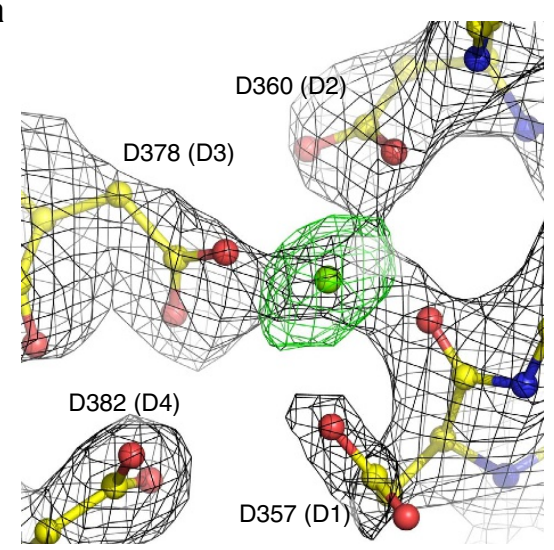

C

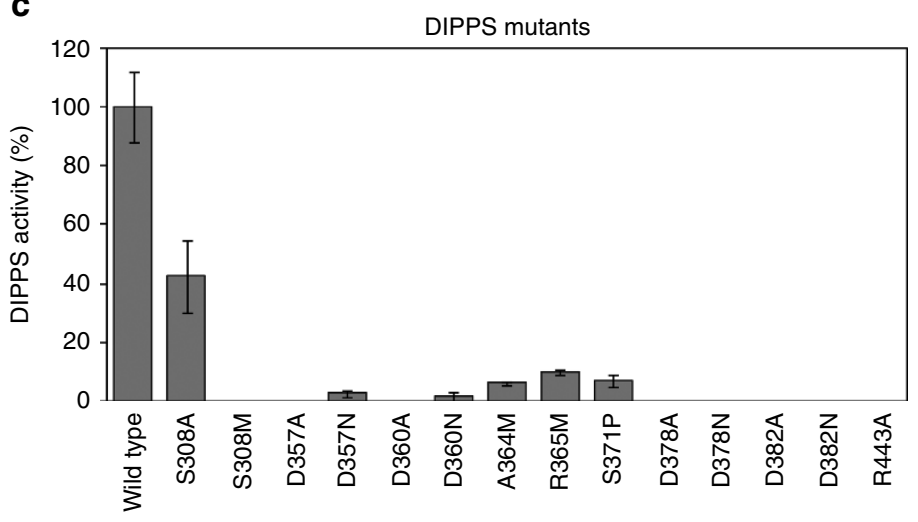

b
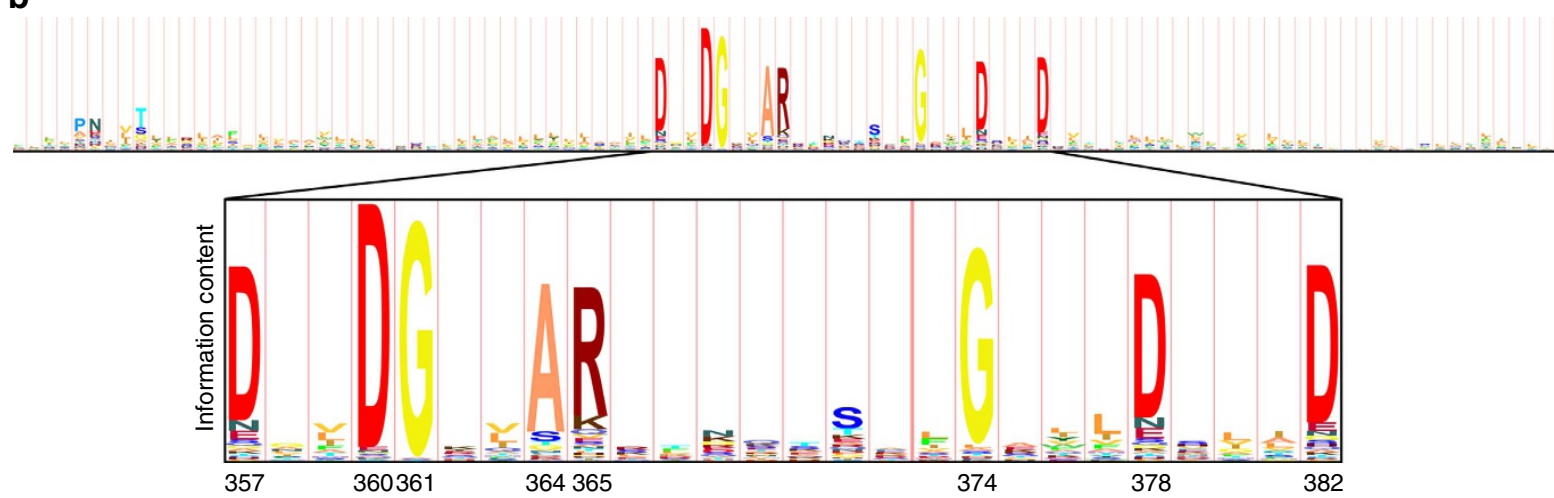

Figure 4 | DIPPS active site along with HMM logo and functional assays. (a) Zoomed view of the electron density map around the conserved aspartate residues. The maps were calculated before insertion of the magnesium ion in the model. The $2 F_{\mathrm{o}}-\mathrm{F}_{\mathrm{c}}$ density is shown in black and contoured at $1.5 \sigma$, the $F_{o}-F_{c}$ density is green and contoured at $3 \sigma$; electron density around Asp357 is not very well defined. (b) HMM logo ${ }^{50}$ around the consensus sequence of CDP-alcohol phosphotransferase family based on the alignment of 124 representative Pfam protein families as seeds ${ }^{51}$. The most conserved residues are located at the intracellular ends of TM2 and TM3. (c) Diagram of DIPPS activity as assessed in 30 min reactions to study the effect of point mutations; values are expressed as \% relative to the wild type enzyme in the presence of $10 \mathrm{mM} \mathrm{Mg}^{2+}$. Values are averages of duplicate experiments derived from independent growths.

(Fig. 5b). We speculate that A364M may obstruct the accessibility to the active site hydrophilic cavity, whereas R365M can affect the capture/binding of the negatively charged substrates. Mutation of equivalent residues (Ala to Gly and Arg to Ala) in Saccharomyces cerevisiae cholinephosphotransferase (CPT) also led to reduced catalytic activity, suggesting that both residues have a role in substrate binding or positioning ${ }^{23}$. Mutation of S371P within TM2-TM3 loop resulted in a significant reduction of the enzyme activity (Fig. 4c). This is probably owing to restraints on the loop flexibility that could affect the substrates entry. A similar result was also observed for the corresponding allele mutation in E. coli phosphatidylglycerophosphate synthase ${ }^{24}$.

Related to pocket 2, we mutated Ser308, a strictly conserved amino-acid residue among enzymes with putative DIPPS activity, located on connector helix 2 that is adjacent to the inositol-1-phosphate binding pocket (Figs $5 \mathrm{c}$ and 6). Decrease of DIPPS activity in S308A may be justified by the loss of H-bonding to the phosphate group of inositol-1-phosphate substrate, whereas enzymatic inactivation by $\mathrm{S} 308 \mathrm{M}$ could result from introducing a bulkier side chain in the putative binding site, thus preventing substrate binding (Fig. 4c). Moreover, Arg443 sits at the bottom of the hydrophilic cavity and is within hydrogen bonding distances to Asp357 and Asp386 carboxylate groups, and one hydroxyl of the fitted inositol-1phosphate and its substitution by alanine (R443A) abolishes DIPPS activity.

\section{Discussion}

The HMM logo sequence of $\mathrm{CDP}-\mathrm{OH}$ phosphotransferases (Fig. 4b) compared with Prosite ${ }^{17}$ reveals the conservation of an extra aspartate residue (D1, Asp357), which is not yet included in the consensus motif of this family. This Asp was also shown to be essential for the catalytic activity of other phosphotransferases $^{25}$, likely having a role in substrate binding and positioning. We therefore propose to add this first aspartate residue in the consensus sequence pattern of $\mathrm{CDP}-\mathrm{OH}$ phosphotransferases, as previously suggested ${ }^{25}$. Furthermore, some phosphatidylcholine synthases were shown to have 12 amino-acid residues between Arg and $\mathrm{Gly}^{25}$, so a more general conserved sequence pattern for CDP-alcohol phosphatidyltransferase family should be $\mathrm{D}(\mathrm{x})_{2} \mathrm{DG}(\mathrm{x})_{2} \mathrm{AR}(\mathrm{x})_{7-12} \mathrm{G}(\mathrm{x})_{3} \mathrm{D}(\mathrm{x})_{3} \mathrm{D}$, to include all members of this family identified thus far (proposed changes highlighted in bold).

Our site-directed mutagenesis studies on the consensus aminoacid residues (Fig. 4b) showed that all four aspartate, alanine and arginine residues are functionally relevant, as their loss abolishes or considerably reduces the catalytic activity (Fig. 4c). These results generally agree with data from the Sinorhizobium meliloti bacterial $\mathrm{CPT}^{25}$, S. cerevisiae CPT1 (ref. 23) and Brassica napus plant aminoalcoholphosphotransferase ${ }^{26}$ (AAPT1), but the degree of reduction in their enzyme activities caused by the mutations may depend on the source and type of assays (in vivo or in vitro). A striking difference occurs when the second Asp 

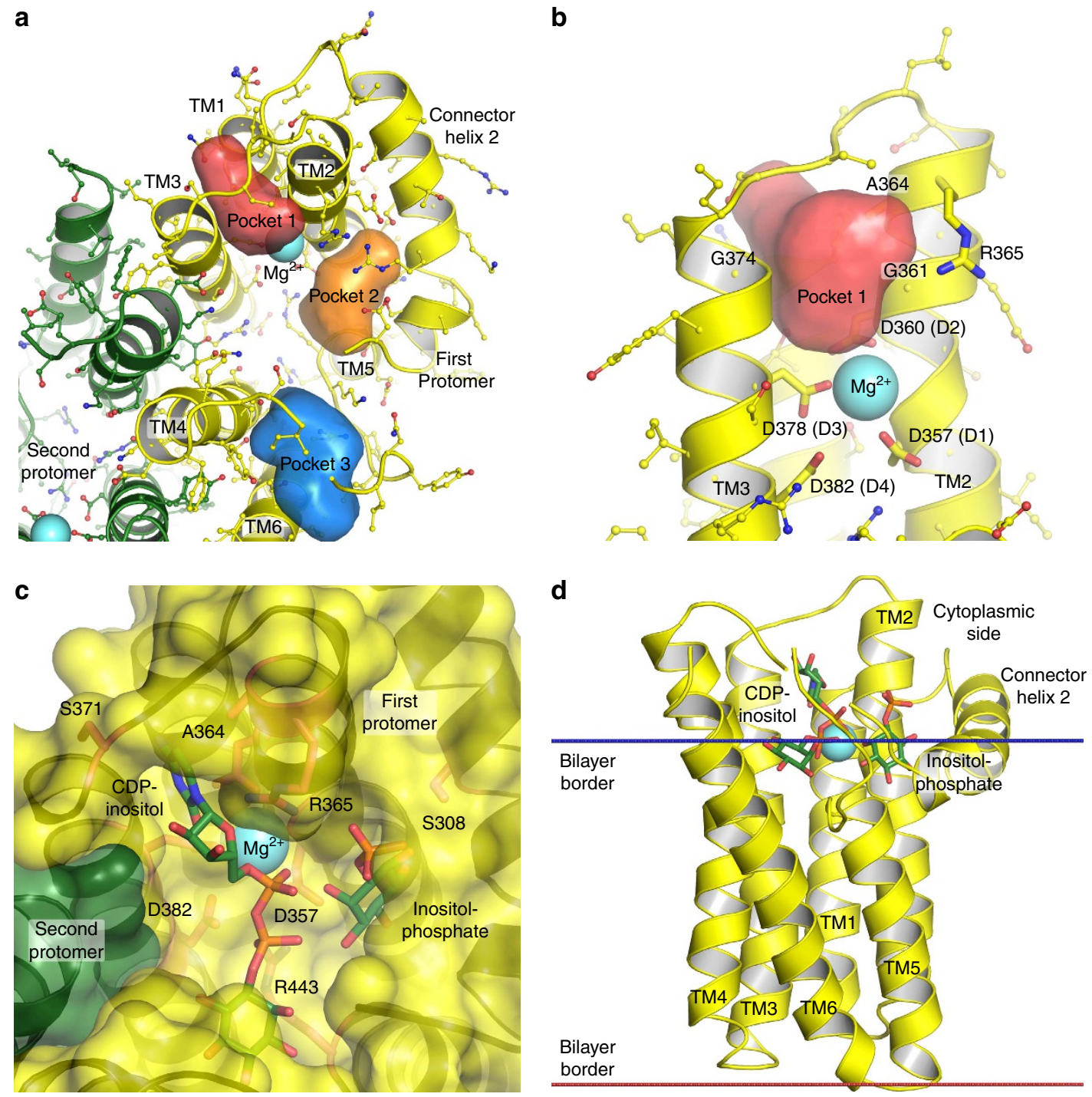

Figure 5 | Pockets visualization and substrate docking. (a) Putative ligand-binding pockets of DIPPS assigned with HOLLOW ${ }^{21}$ (top view from the cytoplasm-facing side). The pockets are shown in pink (1), orange (2) and blue (3). (b) Detailed view of conserved pocket 1. The strictly conserved residues Gly361, Ala364 and Gly374, belonging to the family consensus sequence, form the surface of the pocket. (c) Model with bound ligands in DIPPS domain. The ligands fit well into the surface cavities and are properly oriented. (d) Position of DIPPS substrates relative to the bilayer surface. The CDP moiety is above the bilayer surface, whereas the inositol group of CDP-inositol and inositol-phosphate are slightly underneath it. The membrane position was estimated using the PPM server ${ }^{49}$.

(D2) is substituted by Ala; the small effect observed in yeast CPT1 and plant AAPT1 contrasts with the complete enzyme ablation of archaeal IPCT/DIPPS and bacterial CPT (also observed with D2N mutation). Indeed, this is the most conserved residue within CDP-OH_P_transf (Fig. 4b). These results imply that the eukaryotic CPT1 and AAPT1 should still be able to retain the divalent ion in the catalytic site of D2A mutants. Furthermore, no mutations were performed on the first Asp (D1) of yeast CPT1 and plant AAPT1, as it was not yet considered to be part of the family consensus motif.

Notably, other family of peripheral membrane enzymes named phospholipase $\mathrm{D}$, phosphatidylserine synthase type, which includes $E$. coli phosphatidylserine synthase, prokaryotic cardiolipin synthase, phospholipase D and some nucleases ${ }^{23}$ shares a different motif $\left(\mathrm{HxK}(\mathrm{U})_{4} \mathrm{D}(\mathrm{x})_{4} \mathrm{UUGO}\right)$. These enzymes catalyse the transfer of a substituted phosphate group, other than diphosphate or nucleotidyl residues, from one compound (donor) to another (acceptor). Although they appear capable of forming an identical phosphoester bond ${ }^{27,28}$ they do not require a divalent ion for catalysis and follow a ping-pong reaction type with an enzyme-bound intermediate ${ }^{29-31}$.

In contrast, kinetics studies on members of CDP-alcohol phosphotransferase family, such as synthases of phosphatidylserine from yeast ${ }^{29,32}$ and Bacillus licheniformis ${ }^{33}$, phosphatidylglycerophosphate from E. coli $i^{34}$ and phosphatidylcholine from $\mathrm{rat}^{35}$, suggest a sequential $\mathrm{Bi}-\mathrm{Bi}$ mechanism for these enzymes. Assuming also a single displacement $\mathrm{S}_{\mathrm{N}}$ 2-like mechanism for DIPPS, we propose that Asp357/Asp382 function as base catalysts and promote the direct nucleophilic attack of the hydroxyl group (on C3) of inositol-1-phosphate on the $\beta$-phosphoryl of CDPinositol with formation of DIPP and CMP (Fig. 2).

Remarkably, the membrane character of DIPP synthase is intriguing, as all its substrates and products are water soluble (Fig. 2). A recent evolution analysis of DIPP-synthases has shown that these enzymes evolved from phosphatidylinositol synthases that are membrane proteins, so DIPPS kept the 
$\left\lceil\begin{array}{lllllll}300 & \text { Connector } 2 & 310 & 320 \text { TM1 } & 330 \quad 340\end{array}\right.$

A. fulgidus RANRALVSAAVKGSGDGFISRKI NRKISTRISAAIVNKVNPNQMTLISFLVGASALASFFSIPLAGLLY T. kodakaraensis RARRMLVRT A V KG T G D G F VSRHL NRR।STRVSELLVEKVTPNQMTVVTFLLG।ISALTTLVSLPLAGILY

A. aeolicus KAKKYLVKTA I KGVGDGFISRNLNRKVSTRISPYLVDKFTPNQLTVLTFLLGMFALVAYFSPALGGILL

I. aggregans YARRLYLKRNLVKDSDGVISRYL NRKISTA I S I ALY IFVNPNIVTVVVAIIGVVGALMTMFIDRFGSIMV

R. xylanophilus LSEEM-VLGWAASGN DGPVSRH I NRRISRR I TRRLLTPLSPDQVSLLSFALAALAGLLAAGRLRGGALV

T. maritima EKVYEL I KEGVAC

T. maritima M L RKS T D GW I S L I I NRRFS SR I T N L I LWQIT PNQMSFISFLVGVLAFPFYLLKLPWAGILV

P. fumarii GFESGELLEELLGTLVNAGRSK

P. fumarii

QAAKVAKP T DGPVSRL I NRRVSWRVTRILVVS-NPNAVTIATGVFGVLAALPYLAVDPVAGLLV

**. $*$ *

TM2 360

TM3 380

390

$400 \quad$ TM4 $\quad 410$

A. fulgidus QFS S I L D C D GEIARA S L KMSKK G G Y D S I LDRFVDFLFLA I I ALLYPKTATVAMFAIFGSVMVSYTSEK T. kodakaraensis $Q L S$ S I LDG D D GELARAQLRTSKLGGYVDSILDRYVDGSFLALLAYATINEYFVALLALLGSVMVSYSTER

A. aeolicus QIN SMLDGLDGEVARA Q MRTTKFGAWLDSVLDRYVDFAFLSALAMHLKSMPWVFALFGSVMVSYSTER

l. aggregans I I S S I LD GVDGEIARLYNRTSF I GS I LDHVLDRAVDSLYLVATYYIALSTLILLATSFMG IFLVGYLSAV

R. xylanophilus QLA S IVDGCDGELARARLESSPRGA VFATLDRWADALI SGLALGAGTRAAGYPALAGALLVSYTRAR

T. maritima

T. maritima

$P$. fumarii

P. fumarii

QVSSVLDGVDGELARARNMSSNWGAFFDTMLDRFVDILAVLGLSLYGCLKLWSVLAVSGSLMVYLHSV

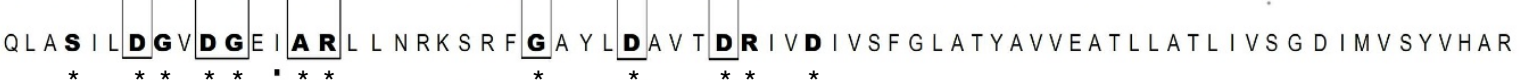

$\begin{array}{llll}* & * & * & * \\ M & M & M & M\end{array}$

M M M

* * *

430

440 TM5

450

460

TM6

470 480

DIPPS domain

A. fulgidus YKAEFGESIFGKFRVLNYIPGKRDERIFLIMIFCLLSA|SLQWIFWMFLFVAAISLTRVVVTLLAVLVSK T. kodakaraensis FRG A F C R D Y K EVP A L RKLPGKR DERVFLTMLFLLYQI - A ASIKALFLTLAVLTNFRVALTLYFVVKKV

A. aeolicus YKGAYCEDAYAVIKELRYLLGKRDERIFMIMIFTILG . . - WIKALFVVLAIITNLRVILTIYLVWKKK

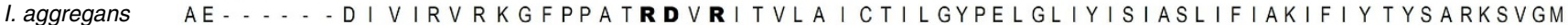

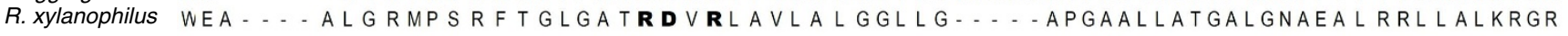

T. maritima

T. maritima GKV - . F G TH PALVGKLSGFA S R D VRLFVVFVFSLFGMHLPALVVISILSYVYTTGKFVELLVLNR

P. fumarii

P. fumarii

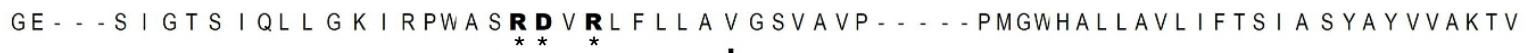

M

Figure 6 | Amino-acid sequence alignment of DIPP-synthases. Alignment was done with Geneious 6.0.3 ref. 52 based on DIPPS sequences from 33 organisms with confirmed or putative DIPP activity ${ }^{12}$. The selected sequences represent the major branches of phylogenetic tree ${ }^{12}$. Examples of products from ipct/dipps genes fused (5) and separated (2). A., Archaeoglobus; T., Thermococcus; A., Aquifex; I., Ignisphaera; R., Rubrobacter; T., Thermotoga; and P., Pyrolobus. Strictly conserved residues among all IPCT/DIPPS sequences are displayed in bold, and from the consensus pattern of CDP-alcohol phosphatidyltransferase family are enclosed in a box. Similar and identical residues are marked, respectively, with a dot and an asterisk beneath, and mutated residues by a red M. Residues involved in pocket formation are highlighted with pink (1), orange (2) and blue (3). Secondary structure elements represented with red tubes ( $\alpha$-helices) were assigned with DSSP53

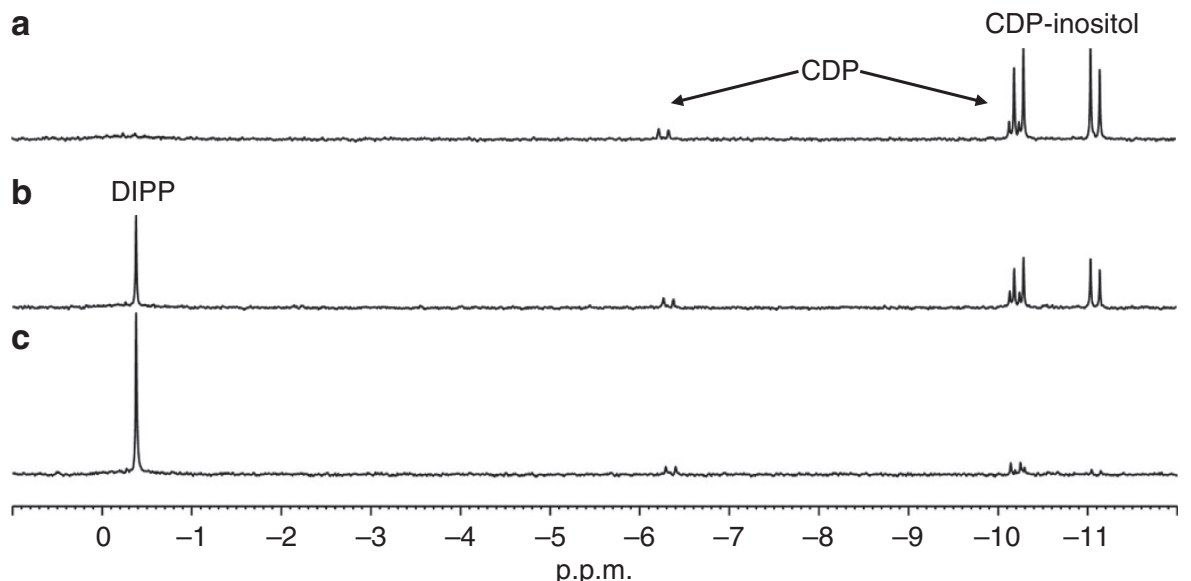

Figure 7 | Activity of the wild type IPCT/DIPPS and mutants assessed by ${ }^{31} \mathbf{P}-\mathbf{N M R}$. The nuclear magnetic resonance spectra show the production of CDP-inositol and DIPP resulting from 30 min incubation at $85^{\circ} \mathrm{C}$ of reaction mixtures containing $2.7 \mathrm{mM}$ of CTP, 7 mM of inositol-1-phosphate and cell extract of E. coli producing A. fulgidus IPCT/DIPPS (0.9 mg of total protein). (a) Point mutation S308M; (b) point mutation S308A; and (c) wild type. Spectra were acquired in a Bruker Avance II 500 spectrometer. 
membrane-spanning character of its ancestor ${ }^{12}$. In contrast, CDP-OH_P_trans enzymes involved in phospholipid biosynthesis usually have a lipophilic substrate that can either be a donor substituent or alcohol acceptor (for example, diacylglycerol $(\mathrm{DAG})$ ) that reacts with a water-soluble one (typically a phospholipid head group, for example, glycerol or serine). However, some enzymes, such as cardiolipin synthases, have two lipidic substrates, CDP-DAG and phosphatidylglycerol. The $\mathrm{X}$-ray structure of IPCT/DIPPS revealed a large polar active site cavity that lies near the membrane interface and should be a common feature to other $\mathrm{CDP}-\mathrm{OH}$ phosphotransferases. This positioning is strategic to allow accommodation and binding of both hydrophilic and lipophilic substrates. The catalytic reaction occurs at the hydrophilic-hydrophobic interface of the membrane with $\mathrm{Mg}^{2+}$ lying on the border (Fig. 5d), so the lipophilic chains of diacylglycerol or other phospholipids could easily be embedded in the lipid bilayer.

We expect a high degree of structural conservation among $\mathrm{CDP}$-alcohol phosphotransferases around the consensus region, located at the $\mathrm{N}$ terminus of their sequences (TM2-TM3 in DIPPS) with subtle or more significant differences on the ligandbinding sites depending on their substrates. Members of this family are involved in the synthesis of phospholipids, which have important roles in cell viability and infectivity of pathogenic bacteria $^{1,2,4,36}$. Therefore, DIPPS structure may be of utmost value to structural homology modelling and in providing molecular targets for the rational design of novel drugs.

\begin{abstract}
Methods
Expression and purification. The A. fulgidus AF0263 gene encoding IPCT/DIPPS was amplified by PCR (forward primer: $5^{\prime}$-TCCCCCCGGGATGATAAATGTTGA CGGAGAATAC-3', XmaI site underlined; reverse primer: $5^{\prime}$-GCGGAGCTCTT TAGAAACCAAAACAGCAAGTAAAG-3', SacI site underlined). The PCR product was cloned into the expression vector pET52b $(+)$ (Novagen) using SacI and $\mathrm{XmaI}$ restriction sites, with N-terminal Strep tag II and C-terminal His $\mathrm{H}_{10}$ tag. The resulting plasmid was verified by DNA sequencing. The expression vector was transformed into E. coli C43 DE3. Cells were cultivated in terrific broth medium at $37^{\circ} \mathrm{C}$ in a 30 -litre fermentor with $\mathrm{pH}$ controlled at 7.4 , and induced with $0.5 \mathrm{mM}$ isopropyl $\beta$-D-1-thiogalactopyranoside when the $\mathrm{OD}_{600}$ reached 1.0. The temperature was subsequently lowered to $30^{\circ} \mathrm{C}$. Cells were harvested $6 \mathrm{~h}$ following induction and resuspended in lysis buffer $(50 \mathrm{mM}$ sodium citrate, $50 \mathrm{mM}$ sodium phosphate, $200 \mathrm{mM} \mathrm{NaCl}, 5 \%$ glycerol, $100 \mathrm{mM}$ sucrose, $1 \mathrm{mM}$ ethylenediaminetetraacetic acid, $0.5 \mathrm{mM}$ phenylmethanesulfonylfluoride, $2 \mathrm{mM} \beta$-mercaptoethanol and protease inhibitors cocktail tablet SIGMAFAST; $\mathrm{pH}$ 7.5). Cells were disrupted using a constant flow cell disruptor, and cell debris and inclusion bodies were removed by centrifugation at $10,000 \mathrm{~g}$ for $30 \mathrm{~min}$. E. coli membranes were isolated by ultracentrifugation at $200,000 \mathrm{~g}$ for $2 \mathrm{~h}$. The protein was extracted from the membranes by solubilization in $2 \%$ Triton X-100, $20 \%$ glycerol, $1 \mathrm{M} \mathrm{NaCl}, 50 \mathrm{mM}$ phosphate buffer, $50 \mathrm{mM}$ imidazole, $100 \mathrm{mM}$ sucrose, $2 \mathrm{mM} \beta$-mercaptoethanol and $1 \mathrm{mM} \mathrm{MgCl}$ (final $\mathrm{pH} 7.4$ at $277 \mathrm{~K}$ ) for $2 \mathrm{~h}$. Insoluble fraction was separated by $1 \mathrm{~h}$ centrifugation at $100,000 \mathrm{~g}$. The supernatant was loaded onto HisTrap HP column (GE Healthcare). The loaded sample was washed with buffer A $(0.1 \%$ Triton X-100, $50 \mathrm{mM}$ phosphate buffer, $50 \mathrm{mM}$ imidazole, $10 \%$ glycerol and $1 \mathrm{M}$ $\mathrm{NaCl}$; $\mathrm{pH}$ 7.4), followed by an additional wash with buffer A supplemented with $110 \mathrm{mM}$ imidazole. The protein was eluted with buffer B containing $0.1 \%$ Triton $\mathrm{X}-100,50 \mathrm{mM}$ phosphate buffer, $500 \mathrm{mM}$ imidazole, $10 \%$ glycerol, $300 \mathrm{mM} \mathrm{NaCl}$ and $1 \mathrm{mM} \mathrm{MgCl} 2 ; \mathrm{pH}$ 7.4. Immediately after elution, the sample was supplemented with $1 \mathrm{mM} \beta$-mercaptoethanol and concentrated to $\sim 20 \mathrm{mg} \mathrm{ml}^{-1}$ in centrifugal filter unit with a membrane of $100 \mathrm{kDa}$ molecular weight cutoff.
\end{abstract}

Biochemical characterization of IPCT/DIPPS. Point mutations were introduced using QuickChange I kit (Agilent Technologies) and confirmed by DNA sequencing (STAB VIDA). Primers designed for the mutants are listed in Supplementary Table 1. The mutants were cultured following a similar protocol as described for the wild type. SDS-PAGE and His-tag western blotting were performed on the membrane preparations from cell extracts, confirming that all mutants were expressed in the E. coli membranes (Supplementary Fig. 5a,b). Protein content was estimated by the Bradford method ${ }^{37}$. Inositol-1-phosphate was produced from glucose-6-phosphate by the activity of A. fulgidus inositol-1-phosphate synthase, and purified by ion exchange chromatography (QAE-Sephadex A-25 and Dowex $50 \mathrm{~W}-\mathrm{X} 8$ resins $)^{8}$.

The IPCT/DIPPS activities were assessed in cell extracts of E. coli C43, harbouring wild type or mutant variants of the ipct/dipps gene from A. fulgidus.
The cell pellets were suspended in $50 \mathrm{mM}$ Bis/Tris/propane- $\mathrm{HCl}(\mathrm{pH} 8.0)$ containing $5 \%(\mathrm{v} / \mathrm{v})$ glycerol and $100 \mathrm{mM} \mathrm{NaCl}$; cells were disrupted in a French press and debris were removed by centrifugation $\left(10,000 \mathrm{~g}, 15 \mathrm{~min}, 4^{\circ} \mathrm{C}\right)$. Reaction mixtures $(0.3 \mathrm{ml})$ containing $25 \mathrm{mM}$ Bis/Tris/propane- $\mathrm{HCl}(\mathrm{pH} 8.0), 10 \mathrm{mM}$ $\mathrm{MgCl}_{2}, 2.7 \mathrm{mM}$ CTP and $7 \mathrm{mM}$ inositol-1-phosphate, and cell extract $(0.9 \mathrm{mg}$ of total protein) were incubated at $85^{\circ} \mathrm{C}$ for 1 and $30 \mathrm{~min}$. The reactions were stopped on ice before the addition of deuterated water $(200 \mu \mathrm{l})$ and $25 \mathrm{mM}$ EDTA $(\mathrm{pH} 8.0)$. The reaction products of IPCT and DIPPS, that is, CDP-inositol and DIPP, respectively, were quantified by ${ }^{31} \mathrm{P}-\mathrm{NMR}$ using diglycerol-phosphate as an internal concentration standard (Fig. 7). Owing to the bifunctionality of IPCT/ DIPPS, the IPCT activity served also as a reliable control for protein production. The concentration of the IPCT product was fairly constant for the 14 mutants examined (Supplementary Fig. 5b). All these assays were performed in duplicate corresponding to independent growths.

Crystallization and structure determination. The crystals of IPCT/DIPPS were grown using an in meso crystallization method ${ }^{13}$, similarly to Gordeliy et al. ${ }^{38}$ The protein-mesophase mixture contained concentrated enzyme solution and monoolein. High-throughput crystallization was performed with NT8 robot (Formulatrix, USA). Plate-like crystals reaching the size of $5 \times 20 \times 200 \mu \mathrm{m}$ were grown in $50 \mathrm{nl}$ protein-containing mesophase drops overlaid by precipitant solution (4-12\% PEG 550-6,000, 0.2-2 M sodium malonate, $\mathrm{pH} 5.8-8.2$ ) at $295 \mathrm{~K}$ for $30-300$ days. The crystals were harvested directly from the mesophase matrix and flashfrozen in liquid nitrogen. The best X-ray diffraction data were collected from two crystals at $100 \mathrm{~K}, 0.8726 \AA$ wavelength, on ID23-1 and ID23-2 beamlines of the European Synchrotron Radiation Facility (Grenoble, France). Data of these two crystals were merged and integrated to $2.65 \AA\left(R_{\text {pim }}\right.$ in the highest resolution shell is $46.9 \%$ with CC of $51.3 \%$ and I/ $\sigma$ I of 1.7 ; Table 1), according to Karplus and Diederichs $^{39}$, with MOSFLM ${ }^{40}$ and scaled using Scala ${ }^{41}$ from CCP4 software suite $^{42}$. Initial phases were obtained via Molecular Replacement with MOLREP ${ }^{43}$ using the crystallographic structure of the soluble domain (PDB ID 2XME) as a starting model. The electron density maps revealed that the soluble domains form layers with a separation of $\sim 70 \AA$ that is enough for the membrane-like layer containing TM domains. Additional search for alpha-helical fragments resulted in establishment of position of five TM alpha-helices. Refinement of the fragments' structure with Refmac5 (ref. 44) and PHENIX ${ }^{45}$ resulted in improvement of the electron density maps, and following identification of the sixth TM helix and two alpha-helices parallel to the membrane plane. Eventually, identities of the side chains were determined. The final R-factors are 24.3 and $30.0 \%\left(R\right.$ and $R_{\text {free }}$, respectively). Ramachandran plot shows that $96.3 \%$ of the amino-acid residues are in favoured regions, $3.2 \%$ are in allowed regions and $0.5 \%$ in not allowed regions. All structural figures were prepared with CCP4mg ${ }^{46}$ and PyMOL ${ }^{47}$.

Molecular docking studies. Autodock Vina software $\mathrm{e}^{22}$ was used for molecular docking along with Autodock/Vina plugin for PyMOL to set up the simulations. Autodock Vina uses as default the Iterated Local Search global optimization algorithm for an efficient global search. For the local optimization, Autodock Vina uses a quasi-Newton, Broyden-Fletcher-Goldfarb-Shanno method. The docking was performed within the axis-aligned bounding box in the cytoplasmic part of the TM domain that contains all three binding pockets visualized using HOLLOW ${ }^{21}$ (Fig. 5a-d). The volume of the search space was $\sim 20,000 \mathrm{~A}^{3}$. During the docking, ligands were flexible, that is, all non-aromatic bonds were rotatable. The magnesium ion was included in the calculations. First, the smaller compound inositol-1-phosphate was docked around pocket 2. During this simulation, four amino-acid residues flanking the binding pocket, Asp296, Ser300, Arg305 and Arg365, were allowed to change their conformations. Then, after inositol-1phosphate was fixed in the best position, CMP docking simulations were run with a single flexible residue, Arg365.

The scoring function used by Autodock Vina is given as a weighted sum of steric interactions, hydrophobic interactions and, where applicable, hydrogen bonding ${ }^{22}$. Because this software energy (scoring) function, similarly to others used in computational docking, is usually not enough to discriminate the correct docking pose from other poses ${ }^{48}$, the 100 top-ranking possible ligand positions were generated by the Vina software, and the best one was chosen according to the biochemical rationales.

\section{References}

1. Gibellini, F. \& Smith, T. K. The Kennedy pathway-De novo synthesis of phosphatidylethanolamine and phosphatidylcholine. IUBMB Life 62, 414-428 (2010).

2. Heath, R. J., White, S. W. \& Rock, C. O. Lipid biosynthesis as a target for antibacterial agents. Prog. Lipid Res. 40, 467-497 (2001).

3. Jackson, M., Crick, D. C. \& Brennan, P. J. Phosphatidylinositol is an essential phospholipid of mycobacteria. J. Biol. Chem. 275, 30092-30099 (2000).

4. Morii, H. et al. Studies of inositol 1-phosphate analogues as inhibitors of the phosphatidylinositol phosphate synthase in mycobacteria. J. Biochem. 153, 257-266 (2013).

5. Kennedy, E. P. \& Weiss, S. B. Function of cytidine coenzymes in the biosynthesis of phospholipides. J. Biol. Chem. 222, 193-213 (1956). 
6. Weiss, S. B., Smith, S. W. \& Kennedy, E. P. Enzymatic formation of lecithin from cytidine diphosphate choline and D-1, 2-diglyceride. J. Biol. Chem. 231, 53-71 (1958).

7. Hermansson, M., Hokynar, K. \& Somerharju, P. Mechanisms of glycerophospholipid homeostasis in mammalian cells. Prog. Lipid Res. 50, 240-257 (2011).

8. Rodrigues, M. V. et al. Bifunctional CTP: Inositol-1-phosphate cytidylyltransferase/CDP-inositol: Inositol-1-phosphate transferase, the key enzyme for di-myo-inositol-phosphate synthesis in several (hyper)thermophiles. J. Bacteriol. 189, 5405-5412 (2007).

9. Rodionov, D. A. et al. Genomic identification and in vitro reconstitution of a complete biosynthetic pathway for the osmolyte di-myo-inositol-phosphate. Proc. Natl Acad. Sci. USA 104, 4279-4284 (2007).

10. Borges, N. et al. Biosynthetic pathways of inositol and glycerol phosphodiesters used by the hyperthermophile Archaeoglobus fulgidus in stress adaptation. J. Bacteriol. 188, 8128-8135 (2006).

11. Faria, T. Q. et al. Design of new enzyme stabilizers inspired by glycosides of hyperthermophilic microorganisms. Carbohydr. Res. 343, 3025-3033 (2008).

12. Gonçalves, L. G. et al. Evolution of the biosynthesis of di-myo-inositol phosphate, a marker of adaptation to hot marine environments. Environ. Microbiol. 14, 691-701 (2012).

13. Landau, E. M. \& Rosenbusch, J. P. Lipidic cubic phases: a novel concept for the crystallization of membrane proteins. Proc. Natl Acad. Sci. USA 93, $14532-14535$ (1996)

14. Matthews, B. W. Solvent content of protein crystals. J. Mol. Biol. 33, 491-497 (1968).

15. Ostermeier, C. \& Michel, H. Crystallization of membrane proteins. Curr. Opin. Struct. Biol. 7, 697-701 (1997).

16. Brito, J. A., Borges, N., Vonrhein, C., Santos, H. \& Archer, M. Crystal structure of Archaeoglobus fulgidus CTP:inositol-1-phosphate cytidylyltransferase, a key enzyme for di-myo-inositol-phosphate synthesis in (hyper)thermophiles. J. Bacteriol. 193, 2177-2185 (2011).

17. Sigrist, C. J. et al. New and continuing developments at PROSITE. Nucleic Acids Res. 41, D344-D347 (2013)

18. Lairson, L. L., Henrissat, B., Davies, G. J. \& Withers, S. G. Glycosyltransferases: structures, functions, and mechanisms. Annu. Rev. Biochem. 77, 521-555 (2008).

19. Auerbach, G. et al. Closed structure of phosphoglycerate kinase from Thermotoga maritima reveals the catalytic mechanism and determinants of thermal stability. Structure 5, 1475-1483 (1997).

20. Krissinel, E. \& Henrick, K. Inference of macromolecular assemblies from crystalline state. J. Mol. Biol. 372, 774-797 (2007).

21. Ho, B. K. \& Gruswitz, F. HOLLOW: generating accurate representations of channel and interior surfaces in molecular structures. BMC Struct. Biol. 8, 49 (2008).

22. Trott, O. \& Olson, A. J. AutoDock Vina: improving the speed and accuracy of docking with a new scoring function, efficient optimization, and multithreading. J. Comput. Chem. 31, 455-461 (2010).

23. Williams, J. G. \& McMaster, C. R. Scanning alanine mutagenesis of the CDPalcohol phosphotransferase motif of Saccharomyces cerevisiae cholinephosphotransferase. J. Biol. Chem. 273, 13482-13487 (1998).

24. Usui, M., Sembongi, H., Matsuzaki, H., Matsumoto, K. \& Shibuya, I. Primary structures of the wild-type and mutant alleles encoding the phosphatidylglycerophosphate synthase of Escherichia coli. J. Bacteriol. 176, 3389-3392 (1994)

25. Solis-Oviedo, R. L., Martinez-Morales, F., Geiger, O. \& Sohlenkamp, C. Functional and topological analysis of phosphatidylcholine synthase from Sinorhizobium meliloti. Biochim. Biophys. Acta 1821, 573-581 (2012).

26. Qi, Q. G., Huang, Y. F., Cutler, A. J., Abrams, S. R. \& Taylor, D. C. Molecular and biochemical characterization of an aminoalcoholphosphotransferase (AAPT1) from Brassica napus: effects of low temperature and abscisic acid treatments on AAPT expression in Arabidopsis plants and effects of overexpression of BnAAPT1 in transgenic Arabidopsis. Planta 217, 547-558 (2003).

27. Koonin, E. V. A duplicated catalytic motif in a new superfamily of phosphohydrolases and phospholipid synthases that includes poxvirus envelope proteins. Trends Biochem. Sci. 21, 242-243 (1996).

28. Ponting, C. P. \& Kerr, I. D. A novel family of phospholipase D homologues that includes phospholipid synthases and putative endonucleases: Identification of duplicated repeats and potential active site residues. Protein Sci. 5, 914-922 (1996).

29. Raetz, C. R. et al. Phospholipids chiral at phosphorus. Steric course of the reactions catalyzed by phosphatidylserine synthase from Escherichia coli and yeast. Biochemistry 26, 4022-4027 (1987).

30. Dechavigny, A., Heacock, P. N. \& Dowhan, W. Sequence and inactivation of the PSS gene of Escherichia coli - phosphatidylethanolamine may not be essential for cell viability. J. Biol. Chem. 266, 5323-5332 (1991).
31. Larson, T. J. \& Dowhan, W. Ribosomal-associated phosphatidylserine synthetase from Escherichia coli: purification by substrate-specific elution from phosphocellulose using cytidine $5^{\prime}$-diphospho-1,2-diacyl-sn-glycerol. Biochemistry 15, 5212-5218 (1976)

32. Bae-Lee, M. S. \& Carman, G. M. Phosphatidylserine synthesis in Saccharomyces cerevisiae. Purification and characterization of membrane-associated phosphatidylserine synthase. J. Biol. Chem. 259, 10857-10862 (1984).

33. Dutt, A. \& Dowhan, W. Purification and characterization of a membraneassociated phosphatidylserine synthase from Bacillus licheniformis. Biochemistry 24, 1073-1079 (1985).

34. Hirabayashi, T., Larson, T. J. \& Dowhan, W. Membrane-associated phosphatidylglycerophosphate synthetase from Escherichia coli-purification by substrate affinity chromatography on cytidine $5^{\prime}$-diphospho-1,2-diacyl-snglycerol sepharose. Biochemistry 15, 5205-5211 (1976).

35. Pontoni, G. et al. Studies on enzyme-substrate interactions of cholinephosphotransferase from Rat-liver. Biochim. Biophys. Acta 836, 222-232 (1985).

36. Conover, G. M. et al. Phosphatidylcholine synthesis is required for optimal function of Legionella pneumophila virulence determinants. Cell. Microbiol. 10, 514-528 (2008).

37. Bradford, M. M. A rapid and sensitive method for the quantitation of microgram quantities of protein utilizing the principle of protein-dye binding. Anal. Biochem. 72, 248-254 (1976).

38. Gordeliy, V. I. et al. Molecular basis of transmembrane signalling by sensory rhodopsin II-transducer complex. Nature 419, 484-487 (2002).

39. Karplus, P. A. \& Diederichs, K. Linking crystallographic model and data quality. Science 336, 1030-1033 (2012).

40. Leslie, A. G. et al. Automation of the collection and processing of X-ray diffraction data-a generic approach. Acta. Crystallogr. D Biol. Crystallogr. 58, 1924-1928 (2002).

41. Evans, P. Scaling and assessment of data quality. Acta. Crystallogr. D Biol. Crystallogr. 62, 72-82 (2006).

42. Winn, M. D. et al. Overview of the CCP4 suite and current developments. Acto Crystallogr. D Biol. Crystallogr. 67, 235-242 (2011).

43. Vagin, A. \& Teplyakov, A. MOLREP: an automated program for molecular replacement. J. Appl. Crystallogr. 30, 1022-1025 (1997).

44. Murshudov, G. N., Vagin, A. A. \& Dodson, E. J. Refinement of macromolecular structures by the maximum-likelihood method. Acta Crystallogr. D Biol. Crystallogr. 53, 240-255 (1997).

45. Adams, P. D. et al. PHENIX: a comprehensive Python-based system for macromolecular structure solution. Acta. Crystallogr. D Biol. Crystallogr. 66, 213-221 (2010).

46. McNicholas, S., Potterton, E., Wilson, K. S. \& Noble, M. E. Presenting your structures: the CCP4mg molecular-graphics software. Acta Crystallogr. D Biol. Crystallogr. 67, 386-394 (2011).

47. DeLano, W. L. T. The PyMOL Molecular Graphics System (0.98ed). DeLano Scientific, San Carlos, CA, USA (2002).

48. Chang, M. W., Ayeni, C., Breuer, S. \& Torbett, B. E. Virtual screening for HIV protease inhibitors: a comparison of AutoDock 4 and Vina. PLoS ONE 5, e11955 (2010).

49. Lomize, M. A., Pogozheva, I. D., Joo, H., Mosberg, H. I. \& Lomize, A. L. OPM database and PPM web server: resources for positioning of proteins in membranes. Nucleic Acids Res. 40, D370-D376 (2012).

50. Schuster-Bockler, B., Schultz, J. \& Rahmann, S. HMM Logos for visualization of protein families. BMC Bioinformatics 5, 7 (2004).

51. Punta, M. et al. The Pfam protein families database. Nucleic Acids Res. 40, D290-D301 (2012).

52. Kearse, M. et al. Geneious Basic: an integrated and extendable desktop software platform for the organization and analysis of sequence data. Bioinformatics $\mathbf{2 8}$, 1647-1649 (2012).

53. Kabsch, W. \& Sander, C. Dictionary of protein secondary structure: pattern recognition of hydrogen-bonded and geometrical features. Biopolymers 22, 2577-2637 (1983).

\section{Acknowledgements}

The work was supported by MC grant (Marie Curie, FP7/2007-2013, no. 211800), EC FP7 grant for the EDICT consortium (HEALTH-201924) and programme 'Chaires d'excellence' edition 2008 of ANR France, CEA(IBS)-HGF(FZJ) STC 5.1 specific agreement. We greatly acknowledge support from Fundação para a Ciência e a Tecnologia (PTDC/BIA-PRO/118535/2010, PTDC/BIA-PRO/103718/2008, PTDC/SAU-NEU/ 103720/2008, PTDC/BIA-MIC/71146/2006, PTDC/BIA-MIC/099963/2008, PTDC/BBB BEP/2532/2012, RECI/BBB-BQB/0230/2012-for National NMR Facility, and fellowship SFRH/BPD/79243/2011 to P.M. and SFRH/BD/61742/2009 to A.M.E.); PEst-OE/EQB/ LA0004/2011 and ONEXIM, Russia. Part of this work was supported by BMBF (PhoNa-Photonic Nanomaterials), Helmholtz (Helmholtz-Gemeinschaft)-Russia (RFBR) Joint Research Groups (HRJRG-401) programme, Federal Target Program «Scientific and academic research cadres of innovative Russia» for 2009-2013 and by the 5top100-programme of the Ministry for Science and Education of Russia. The diffraction 
experiments were performed on the ID23-1 and ID23-2 beamlines at the European Synchrotron Radiation Facility (ESRF), Grenoble, France. We are very grateful to Local Contacts at ESRF, and especially A. Popov, for providing assistance in using these beamlines. Diamond (I03 and I24) and SLS are also acknowledged for X-ray data measurements. We are grateful for the use of the Membrane Protein Laboratory funded by the Welcome Trust (WT089809) at the Diamond Light Source. We thank João Carita for large-scale fermentation (IBET service); Danielle de Sanctis (ESRF) for helping with crystal diffraction screening; Collin McVey, Miguel Pessanha and Cláudio Soares for their discussions; and João Cabral for critical reading of the manuscript.

\section{Author contributions}

M.A., P.N., H.S. and V.G. designed the project; P.N. and N.B. cloned the gene; P.N. expressed, purified and crystallized the protein in detergent and measured preliminary X-ray diffraction data; I.M. supported crystallization and diffraction tests; A.R. crystallized the protein in meso; E.R. helped with the in meso crystallization; I.G. and A.I.

collected crystallographic data and solved the structure; V.B. helped with data collection and structure analysis; I.G., P.N. and S.G. did the modelling and ligand docking studies; P.M. and P.N. constructed mutant proteins; A.M.E., N.B. and H.S. performed the activity assays and produced inositol-1-phosphate; M.A., P.N., I.G. and V.G. analysed the structure and wrote the manuscript. The in meso crystallization and structural work on in meso grown crystals was supervised by V.G. Overall project management was supervised by M.A. and H.S. All authors discussed the results and commented on the manuscript

\section{Additional information}

Accession codes: Coordinates and structure factors have been deposited in the Protein Data Bank with accession code 4MND.

Supplementary Information accompanies this paper at http://www.nature.com/ naturecommunications

Competing financial interests: The authors declare no competing financial interests.

Reprints and permission information is available online at http://npg.nature.com/ reprintsandpermissions/

How to cite this article: Nogly, P. et al. X-ray structure of a CDP-alcohol phosphatidyltransferase membrane enzyme and insights into its catalytic mechanism. Nat. Commun. 5:4169 doi: 10.1038/ncomms5169 (2014). 